\title{
Comparative analyses on epidemiological characteristics of dengue fever in Guangdong and Yunnan, China, 2004-2018
}

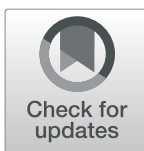

Yujuan Yue ${ }^{1 *+} \mathbb{D}$, Qiyong $\mathrm{Liu}^{1+}$, Xiaobo Liu', Haixia $\mathrm{Wu}^{1}$ and Mingfang $\mathrm{Xu} \mathrm{u}^{1,2}$

\begin{abstract}
Background: In China, Guangdong and Yunnan are the two most dengue-affected provinces. This study aimed to compare the epidemiological characteristics of dengue fever in Guangdong and Yunnan during 2004-2018.

Methods: Descriptive analyses were used to explore the temporal, spatial, and demographic distribution of dengue fever.

Results: Of the 73,761 dengue cases reported in mainland China during 2004-2018, 93.7\% indigenous and 65.9\% imported cases occurred in Guangdong and Yunnan, respectively. A total of 55,970 and 5938 indigenous cases occurred in 108 Guangdong and 8 Yunnan counties, respectively during 2004-2018. Whereas 1146 and 3050 imported cases occurred in 84 Guangdong and 72 Yunnan counties, respectively during 2004-2018. Guangdong had a much higher average yearly indigenous incidence rate $(3.65(1 / 100000)$ vs $0.86(1 / 100000))$, but a much lower average yearly imported incidence rate (0.07 (1/100000) vs 0.44(1/100000)) compared with Yunnan in 2004-2018. Furthermore, dengue fever occurred more widely in space and more frequently in time in Guangdong. Guangdong and Yunnan had similar seasonal characteristics for dengue fever, but Guangdong had a longer peak period. Most dengue cases were clustered in the southwestern border of Yunnan and the Pearl River Delta region in Guangdong. Most of the imported cases (93.9\%) in Guangdong and Yunnan were from 9 Southeast Asian countries. Thailand, Cambodia, and Malaysia imported mainly into Guangdong while Myanmar and Laos imported into Yunnan. There was a strong male predominance among imported cases and an almost equal gender distribution among indigenous cases. Most dengue cases occurred in individuals aged 21-50 years, accounting for 57.3\% (Guangdong) vs. 62.8\% (Yunnan) of indigenous and $83.2 \%$ (Guangdong) vs. 62.6\% (Yunnan) of imported cases. The associated major occupations (house worker or unemployed, retiree, and businessman, for indigenous cases; and businessman, for imported cases), were similar. However, farmers accounted for a larger proportion of dengue cases in Yunnan.
\end{abstract}

Conclusions: Identifying the different epidemiological characteristics of dengue fever in Guangdong and Yunnan can be helpful to formulate targeted, strategic plans, and implement effective public health prevention measures in China.

Keywords: Comparative analyses, Epidemiological characteristics, Temporal, Spatial, Demographic, Guangdong, Yunnan

\footnotetext{
* Correspondence: yueyujuan@icdc.cn

${ }^{+}$Yujuan Yue and Qiyong Liu contributed equally to this work.

'State Key Laboratory of Infectious Disease Prevention and Control, National Institute for Communicable Disease Control and Prevention, Chinese Centre for Disease Control and Prevention, Beijing 102206, People's Republic of China

Full list of author information is available at the end of the article
}

(c) The Author(s). 2021 Open Access This article is licensed under a Creative Commons Attribution 4.0 International License, which permits use, sharing, adaptation, distribution and reproduction in any medium or format, as long as you give appropriate credit to the original author(s) and the source, provide a link to the Creative Commons licence, and indicate if changes were made. The images or other third party material in this article are included in the article's Creative Commons licence, unless indicated otherwise in a credit line to the material. If material is not included in the article's Creative Commons licence and your intended use is not permitted by statutory regulation or exceeds the permitted use, you will need to obtain permission directly from the copyright holder. To view a copy of this licence, visit http://creativecommons.org/licenses/by/4.0/ The Creative Commons Public Domain Dedication waiver (http://creativecommons.org/publicdomain/zero/1.0/) applies to the data made available in this article, unless otherwise stated in a credit line to the data. 


\section{Background}

Dengue fever, one of the most prevalent mosquito-borne diseases in humans, is mainly transmitted by Aedes aegypti and Aedes albopictus [1]. There are four distinct serotypes of dengue virus, namely DENV 1-4 [2]. Dengue fever is endemic in more than 100 countries in Southeast Asia, the Americas, Western Pacific, Africa, and Eastern Mediterranean regions, and has evolved from a sporadic disease to a major public health problem as the geographical spread, numbers of cases, and disease severity increased [3]. It is estimated that 390 million people have dengue virus infections with 96 million cases occurring annually, worldwide [1].

Dengue viruses have spread rapidly within countries and across regions in the past few decades. This has resulted in the increased frequency of epidemics and severe dengue disease, hyper-endemicity of multiple dengue virus serotypes in many tropical countries, and autochthonous transmission in Europe and the USA [3]. Prospective cohort studies in Nicaragua and Thailand indicate an annual incidence of dengue virus infection of 6-29\% [4, 5]. Dengue activity in Africa has increased substantially, and dengue outbreaks in India and the Eastern Mediterranean region have also progressively increased [6]. Most outbreak-associated dengue cases were reported in the Western Pacific Region, particularly after the year 2010; these cases were primarily identified in China, Singapore, and Malaysia [7].

A total of 655,324 cases and 610 deaths were reported in mainland China from 1978 to 2008, and a total of 52, 749 cases and 6 deaths from 2009 to 2014 [8]. A dengue fever outbreak occurred in China in 2014, with 47,127 cases reported, according to Chinese National Notifiable Infectious Disease Reporting Information System (CNNDS) [9]. Dengue fever outbreaks diffused from the southern coastal areas, such as Guangdong (GD) and Hainan to the relatively northern and western areas, including Fujian, Zhejiang, and Yunnan (YN), with shorter outbreak intervals after, than that before the 1990s [10]. The affected regions in China expanded gradually from the coastal provinces to the central provinces over the 10-year period [11].

During 2005-2015, more than $80 \%$ of the total dengue cases in mainland China were reported from GD, YN, Fujian, and Zhejiang. Although the overall number of dengue cases were highest in GD, that in YN had increased in recent years to become the highest contributor in 2015 [12]. During 2005-2014, 94.3\% of the total indigenous cases in mainland China were from GD versus $3.0 \%$ from $\mathrm{YN}$, while $18.3 \%$ of the total imported dengue cases were from GD versus $28.8 \%$ from YN [11]. Therefore, since these highest reported dengue epidemic cases occurred in both GD and YN, China, it is of great importance to the prevention of dengue fever in mainland China to explore the disease characteristics in these areas. However, comparative analyses of such epidemiological characteristics in these areas are rare. Therefore, this study aimed to compare the epidemiological characteristics of the indigenous and imported dengue cases in GD and $\mathrm{YN}$, using descriptive analyses.

\section{Methods}

\section{Data collection}

Dengue case definition was based on clinical diagnosis as well as laboratory confirmation, in line with the diagnostic criteria and principles of the management of dengue fever (WS 216-2001 and WS 216-2008, before and after 2008, respectively; Table 1) [11, 13, 14].

Dengue fever, a vector-borne notifiable disease in China, is reported to Chinese Centre for Disease Control and Prevention (China CDC) through CNNDS. A dengue case report includes information on sex, age, occupation, national code of current address, date of illness onset, remarks, etc. Several occupation categories are reported including farmer, businessman, and student, among others. Daily dengue case reports in GD and YN, China from 1 January, 2004 to 13 December, 2018 were obtained from CNNDS. The vector data from the Chinese administrative divisions that were used for the geographical mapping were obtained from CNNDS. Monthly temperature and monthly rainfall, from 2004 to 2018, were obtained from the Library for Climate Studies of Chinese Meteorological Administration. Gross domestic product (GDP) value in 2018 was obtained from National Bureau of Statistics of China. The population sizes for 2004-2018 were obtained from the Bureaus of Statistics of YN and GD.

\section{Data processing}

Dengue cases were divided into indigenous, imported, and others according to the diagnostic criteria and principles of the management of dengue fever in China. Patients with indigenous dengue fever were defined as those that had not moved out of the local counties (the current addresses), 14 days before the illness onset. Indigenous cases occurred from June to December annually in this study. Imported ones had been to foreign countries or regions where dengue fever was prevalent, 14 days before illness onset. Other cases included those that we were unsure of how to classify. To perform the spatial analysis, dengue cases were aggregated at the county level according to the national codes of the patients' current addresses, and these codes were geocoded and matched to the county-level administrative boundaries using ArcGIS version 10.5 [15].

\section{Data analysis}

Analyses of temporal and demographic distribution were conducted using IBM SPSS Statistics for 
Table 1 Summary of diagnosis criteria and classification for dengue [11]

\begin{tabular}{|c|c|c|}
\hline Variable & $\begin{array}{l}\text { Diagnostic Criteria and Principle of Management of Dengue } \\
\text { Fever }\end{array}$ & Diagnostic Criteria for Dengue Fever \\
\hline Issued by & Chinese Ministry of Health & Chinese Ministry of Health \\
\hline Date issued & 23 November 2001 & 28 February 2008 \\
\hline Date enforced & 1 May 2002 & 1 September 2008 \\
\hline $\begin{array}{l}\text { Epidemiologic } \\
\text { Linkage }\end{array}$ & $\begin{array}{l}1.1 \text { Living in or travel to a dengue endemic country/region or } \\
\text { presence at location with ongoing outbreak within previous } 15 \\
\text { days of dengue-like illness, and reported being bitten by mos- } \\
\text { quito within 5-9 days of illness onset. }\end{array}$ & $\begin{array}{l}\text { 1.1 Travel to a dengue endemic country/region within previous } \\
14 \text { days of dengue-like illness. } \\
1.2 \text { Around the place of residence or place of work (e.g. } 100 \mathrm{~m} \\
\text { radius), there have been dengue case(s) within one month. }\end{array}$ \\
\hline $\begin{array}{l}\text { Clinical } \\
\text { description }\end{array}$ & $\begin{array}{l}\text { 2.1 Sudden onset, chills and fever ( } 39-40^{\circ} \mathrm{C} \text { within } 24-36 \mathrm{~h} \text {, a } \\
\text { small number of patients showed a biphasic fever), with symp- } \\
\text { toms such as fatigue, nausea and/or vomiting. } \\
\text { 2.2 Aches and pains (e.g., headache, retro-orbital pain, joint pain, } \\
\text { myalgia, arthralgia). } \\
\text { 2.3 Flushed skin on face, neck and chest, and conjunctival } \\
\text { congestion. } \\
\text { 2.4 Superficial lymphadenopathy. } \\
\text { 2.5 Measles-like rash, scarlatiniform rash, and/or petechiae in the } \\
\text { limbs, trunk, head and face in the course of illness (days 5-7); } \\
\text { itching; no scaling; continued 3-5d. } \\
\text { 2.6 Encephalitis, encephalopathy, or meningitis-like neurological } \\
\text { disorders. } \\
\text { 2.7 Bleeding tendency (tourniquet test positive): occurs in the } \\
\text { course of illness (days 5-8) with gingival bleeding, nose bleeding, } \\
\text { gastrointestinal bleeding, subcutaneous hemorrhage, hematuria, } \\
\text { hemoptysis, and vaginal bleeding, and/or chest and abdominal } \\
\text { cavity bleeding, etc. } \\
\text { 2.8 Multiple organ bleeding. } \\
\text { 2.9 Liver enlargement. } \\
\text { 2.10 Shock. }\end{array}$ & $\begin{array}{l}\text { 2.1 Sudden onset, fever ( } 39-40^{\circ} \mathrm{C} \text { within } 24-36 \mathrm{~h} \text {, someone } \\
\text { shows biphasic fever); severe headache, retro-orbital pain, myal- } \\
\text { gia, arthralgia and fatigue; flushed skin on face, neck and chest, } \\
\text { and conjunctival congestion, etc. } \\
\text { 2.2 Rash: measles-like rash, scarlatiniform rash, and/or needle-like } \\
\text { hemorrhagic rash in the limbs, trunk, head and face in the course } \\
\text { of illness (days 5-7); itching; no scaling; continued } 3-5 \mathrm{~d} \text {. } \\
\text { 2.3 Bleeding tendency (tourniquet test positive): petechia, } \\
\text { ecchymoses, purpura and injection site bleeding, or bleeding } \\
\text { from the mucous membranes of mouth and nose, } \\
\text { gastrointestinal bleeding, hemoptysis, hematuria and vaginal } \\
\text { bleeding in the course of illness (days 5-8). } \\
\text { 2.4 Massive hemorrhage of gastrointestinal tract, or chest and } \\
\text { abdominal cavity bleeding, or intracranial hemorrhage. } \\
2.5 \text { Liver enlargement, pleural or pericardial effusion. } \\
\text { 2.6 Shock syndrome: clammy skin, restlessness, rapid and weak } \\
\text { pulse and narrow pulse pressure }<20 \text { mmHg ( } 2.7 \mathrm{kPa} \text { ) and } \\
\text { undetectable in blood pressure, oliguria etc. }\end{array}$ \\
\hline $\begin{array}{l}\text { Diagnosis and } \\
\text { Classification }\end{array}$ & $\begin{array}{l}\text { 3.1 Thrombocytopenia (< } 100 \times 109 / \mathrm{L}) \text {. White blood cell count } \\
\text { decrease, lymphocytes and mononuclear cell count increase. } \\
\text { 3.2 Hematocrit increased more than } 20 \% \text {. } \\
\text { 3.3 IgG anti-DENV positive in a serum specimen. } \\
\text { 3.4 lgM anti-DENV positive in a serum specimen. } \\
3.5 \mathrm{lgG} \text { anti-DENV } \geq 4 \text {-fold rise in titer in paired acute and conva- } \\
\text { lescent serum specimens. The serologic tests included enzyme- } \\
\text { linked immunosorbent assay (ELISA), HI, CF, immunofluorescence } \\
\text { method (FA/IFA), Dengue blot (DB), and NT. } \\
\text { 3.6 Cell culture isolation of DENV by Aedes albopictus C6/36 cell } \\
\text { or 1-3 day-old newborn mice; or detection of DENV nucleic acid } \\
\text { by RT-PCR; or detection of antigens by monoclonal antibodies } \\
\text { immunofluorescence (mbAb-FIA) in serum, cerebrospinal fluid } \\
\text { (within } 5 \text { days of illness course), other body fluid or tissue. }\end{array}$ & $\begin{array}{l}\text { 3.1 A total white blood cell count decrease. } \\
\text { 3.2 Thrombocytopenia (< } 100 \times 109 / L \text { ). } \\
\text { 3.3 Hemoconcentration (an increase in hematocrit } \geq 20 \% \text { above } \\
\text { average for age or a decrease in hematocrit } \geq 20 \% \text { of baseline } \\
\text { following fluid replacement therapy); hypoproteinemia. } \\
\text { 3.4 lgG or IgM anti-DENV positive in a serum specimen. } \\
\text { 3.5 Cell culture isolation of DENV by Aedes } \\
\text { albopictus C6/36 cell or } 1-3 \text { day-old newborn mice in acute } \\
\text { serum, cerebrospinal fluid, blood, or other tissue specimens. } \\
\text { 3.6 IgG anti-DENV } \geq 4 \text {-fold rise in titer in paired acute and conva- } \\
\text { lescent serum samples. The serologic tests included ELISA, mac- } \\
\text { ELISA, HI, FA/IFA, NT. } \\
\text { 3.7 Detection of DENV nucleic acid by RT-PCR or real-time fluor- } \\
\text { escence quantitative PCR. }\end{array}$ \\
\hline $\begin{array}{l}\text { Diagnosis and } \\
\text { Classification }\end{array}$ & $\begin{array}{l}\text { 4.1 Suspected case: a patient with item 1.1, } 2.1 \text { and 2.2, and one } \\
\text { of item } 2.3 \text { to } 2.7 \text {, as defined above. } \\
4.2 \text { Probable case: a suspected case with item } 3.1 \text { in a confirmed } \\
\text { outbreak, or a suspected case with item } 3.1 \text { and } 3.3 \text { in an } \\
\text { unconfirmed outbreak or presented as a sporadic case. } \\
\text { 4.3 Confirmed case: } \\
\text { DF: a probable case with one of item 3.4, } 3.5 \text { and 3.6. } \\
\text { DHF: a confirmed DF case with item 2.8, } 2.9 \text { and 3.2. } \\
\text { DSS: a confirmed DHF case with item 2.10. }\end{array}$ & $\begin{array}{l}\text { 4.1 Suspected case: a patient with item } 1.1 \text { and } 2.1 \text {, or a patient } \\
\text { with item } 2.1,3.1 \text { and } 3.2 \text {, as defined above. } \\
4.2 \text { Probable case: } \\
\text { DF: a suspected case with } 1.2,3.1 \text { and } 3.2 \text {; or a suspect case with } \\
\text { item 2.1, 3.1, 3.2 and 3.4. } \\
\text { DHF: a probable case of DF with item } 3.2,3.3 \text { and one of item } \\
2.3 \text { to } 2.5 \text {. } \\
\text { DSS: a probable case of DHF with item } 2.6 \text {. } \\
4.3 \text { Confirmed case: a probable case with one of item } 3.5 \text { to } 3.7 \text {. }\end{array}$ \\
\hline
\end{tabular}

Windows, version 24.0 (IBM Corp., Armonk, N.Y., USA). The chi-square test was used to compare the overall discrepancies of dengue cases by sex, age group, and occupation distributions in GD and YN, 2004-2018. Significant statistical differences between groups were reported at $P \leq 0.05$. Spatial distribution analyses for the dengue cases were conducted using ArcGIS version 10.5 [15].

\section{Results}

Differences in the general information between GD and YN, in China, are shown in Table 2. The population ratio between GD and YN was 2.3, but the area ratio was only 0.5 . Compared with YN, GD had a slightly smaller number of districts and counties. The average yearly incidence rate of indigenous dengue fever in GD, 20042018 , reached $3.65(1 / 100000)$, while that in $\mathrm{YN}$ was 
Table 2 General information comparison between GD and YN, China

\begin{tabular}{llllll}
\hline & $\begin{array}{l}\text { Population } \\
\text { in } \mathbf{2 0 1 0}\end{array}$ & Area $\left.\mathbf{( k m}^{2}\right)$ & $\begin{array}{l}\text { Administrative } \\
\text { divisions }\end{array}$ & $\begin{array}{l}\text { Average yearly incidence rate } \\
\text { of indigenous dengue fever } \\
\text { in 2004-2018 (1/100000) }\end{array}$ & $\begin{array}{l}\text { Average yearly incidence rate } \\
\text { of imported dengue fever in } \\
\mathbf{2 0 0 4 - 2 0 1 8}(\mathbf{1 / 1 0 0 0 0 0 )}\end{array}$ \\
\hline GD & $104,409,400$ & 177,548 & 123 counties in 21 cities & 3.65 & 0.07 \\
YN & $46,016,000$ & 383,966 & 129 counties in 16 cities & 0.86 & 0.44 \\
\hline
\end{tabular}

$0.86(1 / 100000)$. However, the average yearly incidence rate of imported dengue fever in GD, 2004-2018, reached $0.07(1 / 100000)$, while that in $\mathrm{YN}$ was 0.44 (1/ $100000)$. There were 73,761 dengue cases in mainland China during 2004-2018, among which 93.7\% indigenous dengue cases, and $65.9 \%$ imported dengue cases occurred in GD and $\mathrm{YN}$, respectively.

\section{Comparative analyses of indigenous dengue fever in GD} and YN

Temporal comparative analyses of indigenous dengue fever There were 55,970 and 5938 indigenous dengue cases in GD and YN during 2004-2018, respectively. Indigenous dengue cases increased in number in recent years (Fig. 1a).
The indigenous cases and affected counties both showed a seasonal pattern from July to November (Fig. 1b). No indigenous cases occurred in GD, in 2005. Indigenous cases occurred in YN only in 2008 and 2013-2018. The yearly indigenous incidence rate in YN reached a peak of 4.07 (1/ 100000 ) in 2017. In the 2014 dengue fever outbreak in GD, 44,795 indigenous cases, which accounted for $80.0 \%$ of the indigenous cases in GD during 2004-2018, were reported, and the yearly indigenous incidence rate was 41.77 (1/ 100000). There were more indigenous affected counties in GD than that in YN each year in 2004-2018 except in 2005. The monthly indigenous incidence rate and the number of affected counties in GD, in October 2014, reached the highest at $209.86(1 / 1000000)$ and 97, respectively.

a

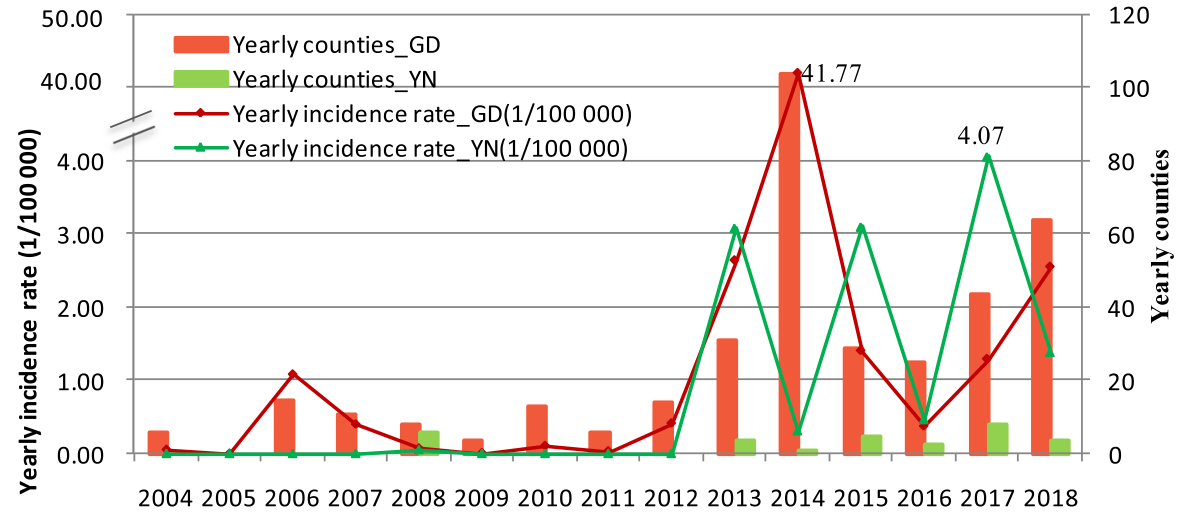

Date

b

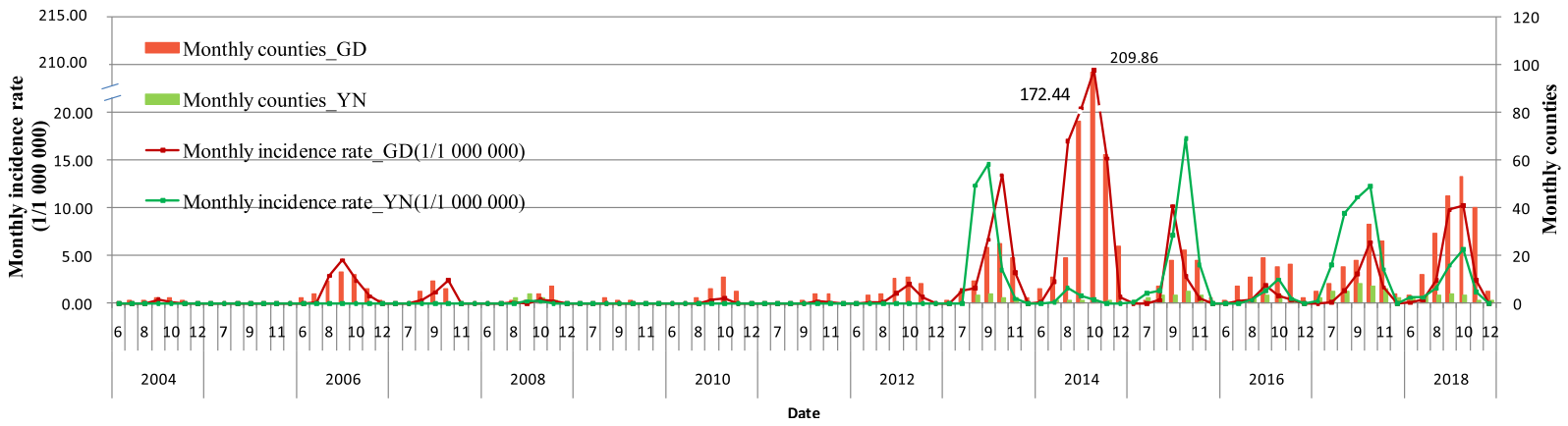

Fig. 1 Temporal distribution mapping of indigenous dengue fever in GD and YN, 2004-2018. a Yearly indigenous fever. b Monthly indigenous fever 
Spatial comparative analyses of indigenous dengue fever YN is in south-western China, while GD is in southern China (Fig. 2a). Compared with 108 indigenous affected counties in GD (87.8\% of its total number of counties), there were 8 indigenous affected counties in YN $(6.2 \%$ of its total number of counties). Most indigenous cases in YN were clustered in the south-western border, while those in GD were clustered in the Pearl River Delta region. The top two yearly average indigenous incidence rates in YN were $48.76(1 / 100000)$ in Jinghong City, Xishuangbanna Dai Autonomous Prefecture; and 46.10 (1/10000) in Ruili City, Dehong Dai Jingpo Autonomous Prefecture. Indigenous cases in Jinghong City and Ruili City accounted for $85.1 \%$ of indigenous cases in YN, 2004-2018. The top two average yearly indigenous incidence rates in GD were $45.84(1 / 100000)$ in Liwan county, Guangzhou City and 37.06 (1/100000) in Baiyun County, Guangzhou City (Fig. 2b).

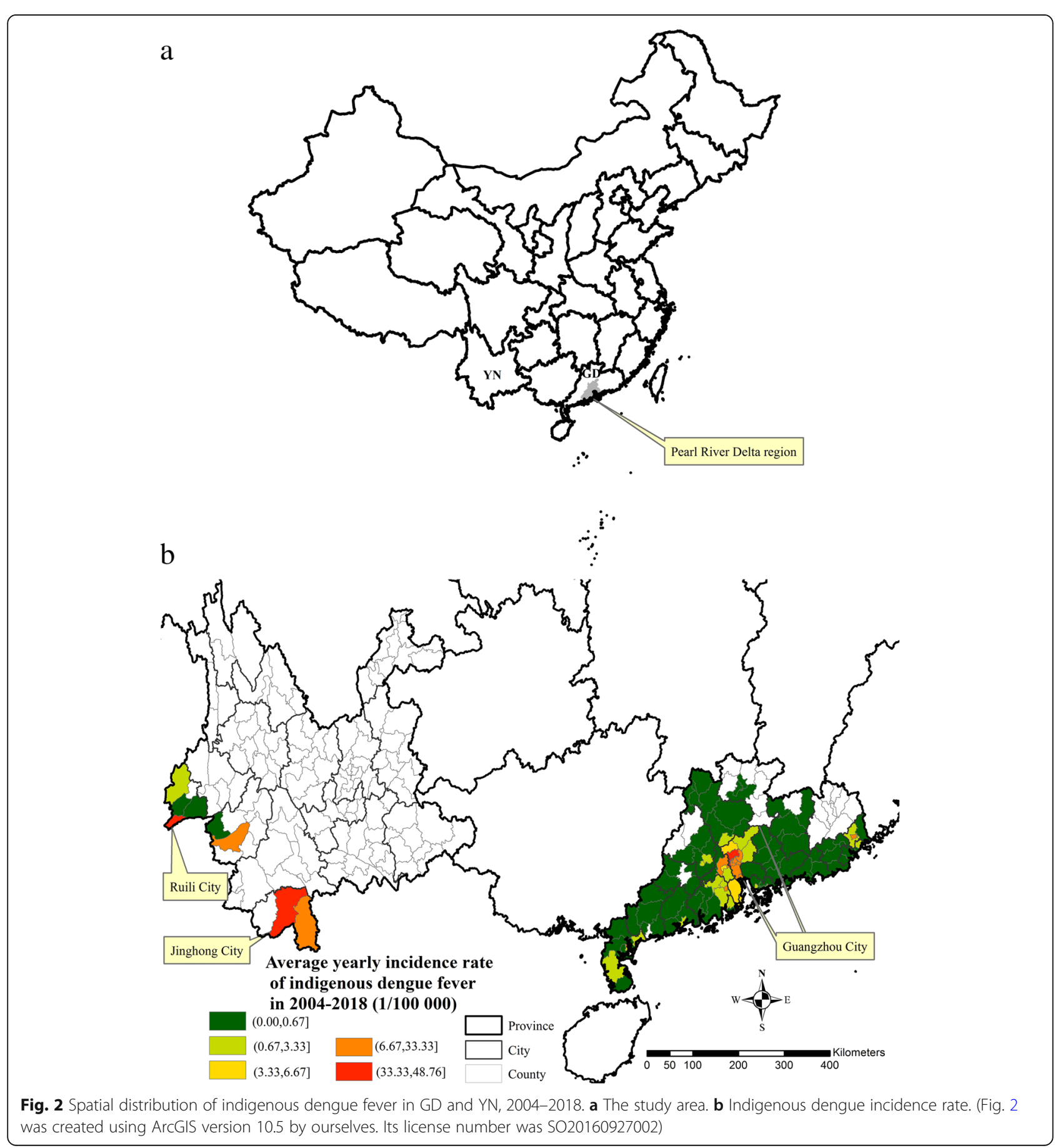




\section{Demographic comparative analyses of indigenous dengue} fever

By gender, the composition of the total indigenous cases in GD differed significantly from that in YN during 2004-2018 (chi-square test $=6.353, P=0.012 \quad[<0.05]$, Table 3 ). There were slightly more female indigenous cases than male indigenous cases both in GD and YN.

By age group, the composition of the total indigenous dengue cases in GD differed significantly from those in YN during 2004-2018 (chi-square test $=2.202 \mathrm{E} 2, P=$ $0.000[<0.05]$, Table 4). Most indigenous cases occurred in individuals aged 21-50 years, accounting for 57.3 and $62.8 \%$ of indigenous cases in GD and YN, respectively. The largest proportions were in individuals aged 21-30 years.

By occupational categories, the composition of the total indigenous dengue cases in GD differed significantly from that in YN during 2004-2018 (chi-square test $=2.153 \mathrm{E} 3, P=0.000[<0.05]$, Table 5$)$. In GD, the top 4 occupational categories for indigenous cases were among house worker or unemployed (23.3\%), retiree, (12.6\%) businessman (11.3\%), and worker (9.9\%). However, in YN, the top 4 occupational categories for indigenous cases were among businessman (24.0\%), farmer (13.6\%), house worker or unemployed (12.8\%), and retiree $(9.2 \%)$.

\section{Comparative analyses of imported dengue fever in GD and YN \\ Temporal comparative analyses of imported dengue fever}

There were 1146 and 3050 imported dengue cases in GD and YN during 2004-2018, respectively. The number of imported dengue fever cases increased progressively in recent years (Fig. 3a). No imported case occurred in YN in 2004. There were imported cases in GD throughout the study period (2004-2018). The yearly imported incidence rate reached a peak of 3.06 (1/ 100000) in $\mathrm{YN}$ in 2017. There were 1468 cases in $\mathrm{YN}$ in 2017, accounting for $48.1 \%$ of its imported cases in 2004-2018. Then the yearly imported incidence rate in GD reached the peak of $0.29(1 / 100000)$ in 2018. There were more imported cases and affected counties in GD than those in YN, yearly, from 2004 to 2018. The monthly imported incidence rate in $\mathrm{YN}$ reached the highest at $11.52(1 / 1000000)$ in October 2017. The peak periods of imported cases and affected counties in $\mathrm{YN}$ were both from July to December; however, those in GD were from May to December (Fig. 3b).

\section{Spatial comparative analyses of imported dengue fever}

Compared with 84 counties in GD $(68.3 \%$ of its total counties) with imported dengue cases, there were 72 affected counties in YN (55.8\% of its total counties). Most imported cases in YN were clustered in the southwestern border, while those in GD were clustered in the Pearl River Delta region. The highest average yearly imported incidence rate (64.41 [1/100000]) occurred in Ruili City, Dehong Dai Jingpo Autonomous Prefecture. The average yearly imported incidence rate of more than $0.67(1 / 100000)$ was reported in the border areas of Xishuangbanna City, Lincang City, and Dehong City. The average yearly imported incidence rates in counties in GD were all below 0.67 (Fig. 4).

Imported cases in GD could be traced to 42 countries, 19 of which also accounted for the number of imported cases in YN. Nine countries from Southeast Asia (Vietnam, Laos, Cambodia, Thailand, Myanmar, Malaysia, Singapore, Indonesia, and Philippines) were the major contributors, with 3939 imported cases $(93.9 \%$ of the total imported cases). There were 2854 imported cases from Myanmar (68.0\% of the total imported cases). From each of Laos, Thailand, Malaysia, Indonesia, and Cambodia, 100-300 imported cases occurred (Fig. 5). Thailand, Cambodia, and Malaysia were the top 3 sources of imported cases in GD with 220, 171 and 152 cases, respectively. Myanmar, Laos, and Thailand were the top 3 sources of imported cases in YN, with 2793, 122 , and 49 cases, respectively.

\section{Demographic comparative analyses of imported dengue fever}

By gender, the composition of the total imported dengue cases in GD differed significantly from that of YN during 2004-2018 (chi-square test $=57.962, P=0.000 \quad[<0.05]$, Table 3$)$. In both provinces, there were more males with imported cases than with the female.

By age group, the composition of the total imported dengue cases in GD differed significantly from that in YN during 2004-2018 (chi-square test $=2.270 \mathrm{E} 2, P=$ $0.000[<0.05]$, Table 4). Most imported cases were in individuals aged $21-50$ years, accounting for $83.2 \%$ in GD

Table 3 Information comparison of dengue fever by gender in GD and YN, 2004-2018

\begin{tabular}{llll}
\hline Gender & \multicolumn{2}{l}{ Indigenous cases/proportions(\%) } & \multicolumn{2}{l}{ Imported cases/proportions(\%) } & GD \\
\cline { 2 - 4 } & GD & YN & $765 / 66.8$ \\
Male & $27,760 / 49.6$ & $2843 / 47.9$ & $381 / 33.2$ \\
Female & $28,210 / 50.4$ & $3095 / 52.1$ & $1638 / 53.7$ \\
Total & $55,970 / 100.0$ & $5938 / 100.0$ & $1412 / 46.3$ \\
\hline
\end{tabular}


Table 4 Information comparison of dengue fever by age group in GD and YN, 2004-2018

\begin{tabular}{lllll}
\hline $\begin{array}{llll}\text { Age } \\
\text { group }\end{array}$ & \multicolumn{2}{l}{ Indigenous cases/proportions(\%) } & & \multicolumn{2}{l}{ Imported cases/proportions(\%) } \\
\cline { 2 - 3 } & GD & YN & $8 / 0.7$ & $294 / 9.6$ \\
\hline $0-10$ & $2661 / 4.8$ & $287 / 4.8$ & $60 / 5.2$ & $444 / 14.6$ \\
$11-20$ & $4675 / 8.4$ & $635 / 10.7$ & $379 / 33.1$ & $842 / 27.6$ \\
$21-30$ & $12,003 / 21.4$ & $1350 / 22.7$ & $369 / 32.2$ & $600 / 19.7$ \\
$31-40$ & $10,267 / 18.3$ & $1196 / 20.1$ & $206 / 18.0$ & $467 / 15.3$ \\
$41-50$ & $9782 / 17.5$ & $1182 / 19.9$ & $83 / 7.2$ & $258 / 8.5$ \\
$51-60$ & $7539 / 13.5$ & $710 / 12.0$ & $34 / 3.0$ & $107 / 3.5$ \\
$61-70$ & $5019 / 9.0$ & $348 / 5.9$ & $7 / 0.6$ & $38 / 1.2$ \\
$71-$ & $4024 / 7.2$ & $230 / 3.9$ & $1146 / 100.0$ & $3050 / 100.0$ \\
Total & $55,970 / 100.0$ & $5938 / 100.0$ &
\end{tabular}

and $62.6 \%$ in $\mathrm{YN}$. The largest proportions were in individuals aged $21-30$ years.

By occupational categories, the composition of the total imported dengue cases in GD differed significantly from that in YN during 2004-2018 (chi-square test $=$ 1.027E3, $P=0.000[<0.05]$, Table 5). In GD, the top 3 occupational categories for imported cases were among businessman (26.3\%), worker (16.8\%), and house worker or unemployed (15.2\%). However, in YN the top 3 occupational categories for imported cases were among farmer (36.8\%), businessman (23.3\%), and student (12.6\%).

\section{Discussion}

During 2004-2018, dengue fever occurred mostly in GD and $\mathrm{YN}$, accounting for $93.7 \%$ of indigenous cases and $65.9 \%$ of imported cases in mainland China. Dengue fever is closely related to population density and mobility, as well as economic and traffic development [16-19].
GD has a much smaller area but a larger population (Table 2). GD also has a much more developed economy (Table 6). YN is on the border next to Myanmar, where dengue fever was more endemic. Above all, because of the different spatial locations and social conditions, GD had a much higher average yearly incidence rate of indigenous dengue fever, but a much lower average yearly incidence rate of imported dengue fever during 20042018. Furthermore, dengue fever occurred more widely in space and more frequent in time in GD.

GD and YN had similar seasonal patterns for dengue fever, with a longer peak period in GD. They also had similar seasonal patterns for temperature and rainfall (Fig. 6). Dengue fever is closely related to climatic factors such as temperature and rainfall $[12,18,19]$. YN borders a torrid zone, with annual rainfall of $800-1600$ $\mathrm{mm}$. The southern region of GD borders a sub-torrid zone, with annual rainfall of more than $1600 \mathrm{~mm}$. These similar climates are responsible for the similar seasonal

Table 5 Information comparison of dengue fever by occupation group in GD and YN, 2004-2018

\begin{tabular}{|c|c|c|c|c|}
\hline \multirow[t]{2}{*}{ Occupation } & \multicolumn{2}{|c|}{ Indigenous cases/proportions(\%) } & \multicolumn{2}{|c|}{ Imported cases/proportions(\%) } \\
\hline & $\overline{\mathrm{GD}}$ & YN & $\overline{G D}$ & YN \\
\hline Cadre & $1740 / 3.1$ & $278 / 4.7$ & $102 / 8.9$ & $49 / 1.6$ \\
\hline Worker & $5566 / 9.9$ & $322 / 5.4$ & 193/16.8 & $97 / 3.2$ \\
\hline House worker or unemployed & $13,030 / 23.3$ & $760 / 12.8$ & $174 / 15.2$ & $199 / 6.5$ \\
\hline Retiree & $7065 / 12.6$ & $546 / 9.2$ & $39 / 3.4$ & 18/0.6 \\
\hline Rural laborer & 1046/1.9 & $149 / 2.5$ & $16 / 1.4$ & $75 / 2.5$ \\
\hline Farmer & $2957 / 5.3$ & $807 / 13.6$ & $31 / 2.7$ & $1122 / 36.8$ \\
\hline Businessman & $6336 / 11.3$ & $1427 / 24.0$ & $301 / 26.3$ & $712 / 23.3$ \\
\hline Student & $4287 / 7.7$ & $480 / 8.1$ & $58 / 5.1$ & $384 / 12.6$ \\
\hline Children & $1463 / 2.6$ & $140 / 2.4$ & $6 / 0.5$ & $155 / 5.1$ \\
\hline Else & $1652 / 3.0$ & $367 / 6.2$ & $54 / 4.7$ & $76 / 2.5$ \\
\hline Unavailable & $10,828 / 19.3$ & $662 / 11.1$ & $172 / 15.0$ & $163 / 5.3$ \\
\hline Total & $55,970 / 100.0$ & $5938 / 100.0$ & $1146 / 100.0$ & $3050 / 100.0$ \\
\hline
\end{tabular}


a

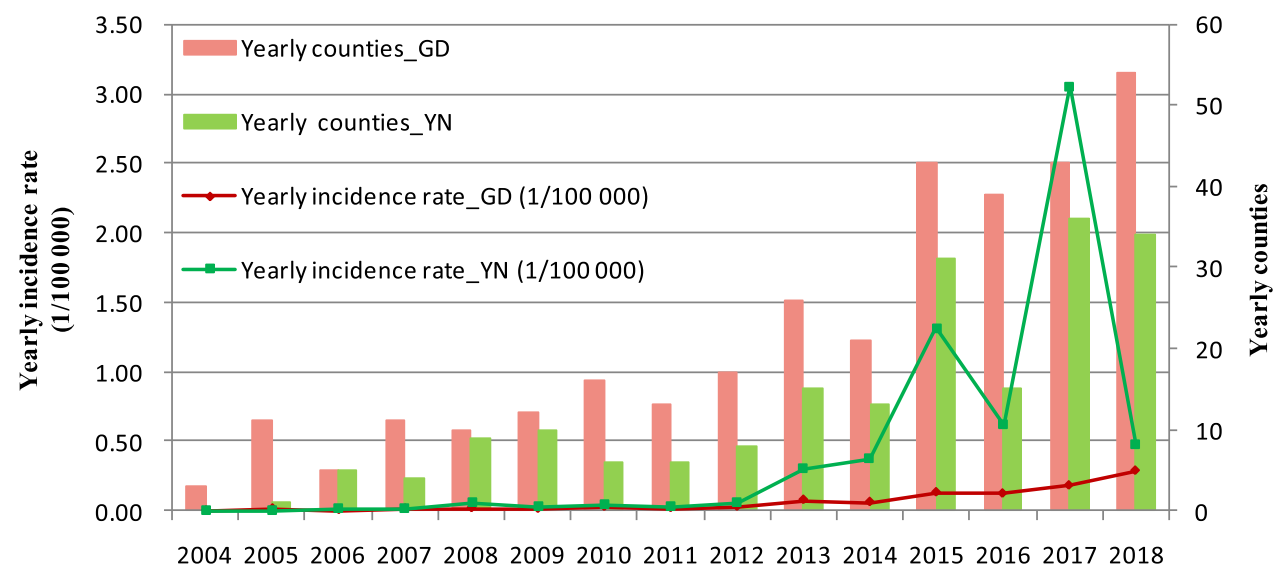

Date

b

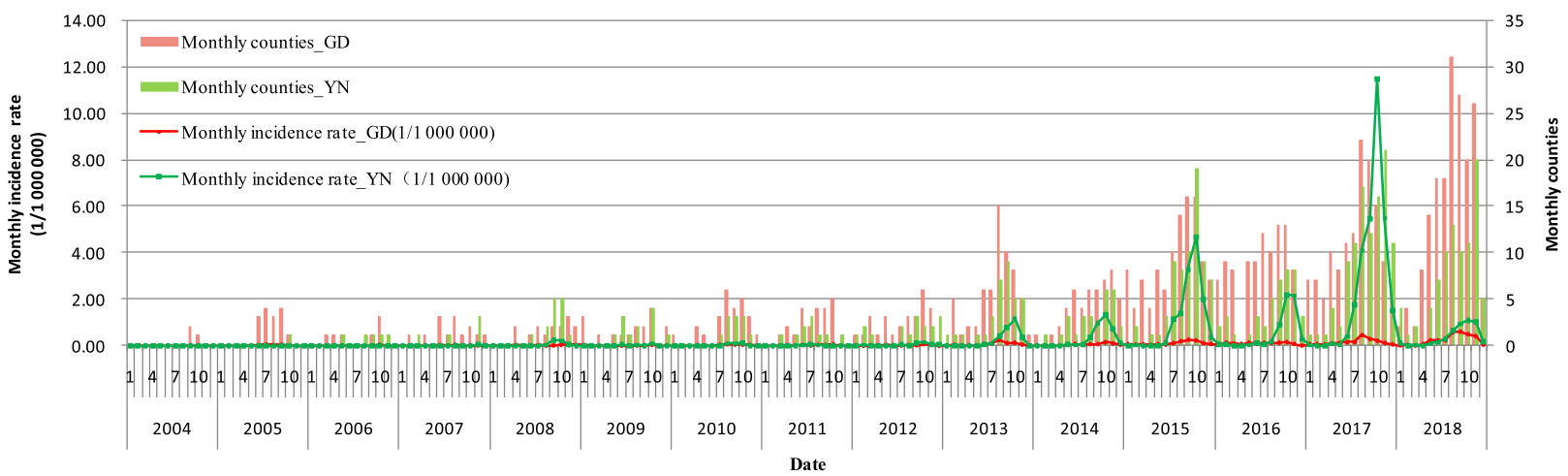

Fig. 3 Temporal distribution mapping of imported dengue fever in GD and YN, 2004-2018. a Yearly imported fever. b Monthly imported fever

patterns of indigenous dengue fever [20]. However, imported dengue fever is more related to the economy, population migration, business, and travel, and GD had a much broader imported sources of dengue fever.

High dengue incidence rates in GD occurred in the Pearl River Delta region, especially in Guangzhou City, which is the capital city of GD. High dengue incidence rates in $\mathrm{YN}$ occurred along the south-western border adjacent to Myanmar, Laos, and Vietnam, especially in Ruili City and Jinghong City. The $93.9 \%$ of the total imported cases in GD and YN occurred from 9 Southeast Asian countries where dengue fever was more endemic [21-24]. Thailand, Cambodia, and Malaysia were the top three sources of imported cases in GD. Myanmar and Laos were the main sources of imported cases in YN. Dengue outbreaks were triggered by imported cases [25]. Thus, both imported and indigenous cases were clustered in similar regions in GD and YN. Therefore, we should focus on the disease prevention and monitoring at the south-western border of $\mathrm{YN}$ and the Pearl
River Delta region of southern GD; especially Ruili City and Jinghong City in YN, as well as Guangzhou City in GD.

By gender, there was a strong male predominance among imported cases and an almost equal gender distribution for indigenous cases. By age group, most of the dengue cases were among individuals aged $21-50$ years (83.2\% of the imported cases in GD). This might reflect a population of young working male adults who tend to travel more domestically and regionally and thereby have more exposure risk to dengue [11]. In addition, both indigenous and imported cases occurred across all age groups in GD and $\mathrm{YN}$, which is different from the pattern in other South-eastern Asian countries where most dengue cases occur among children or younger adults [26]. The pattern is most likely because dengue was not endemic in China and the population in China had very low sero-prevalence of dengue antibodies, whereas the populations in endemic countries have higher rates of immunity, especially in adults and the elderly 


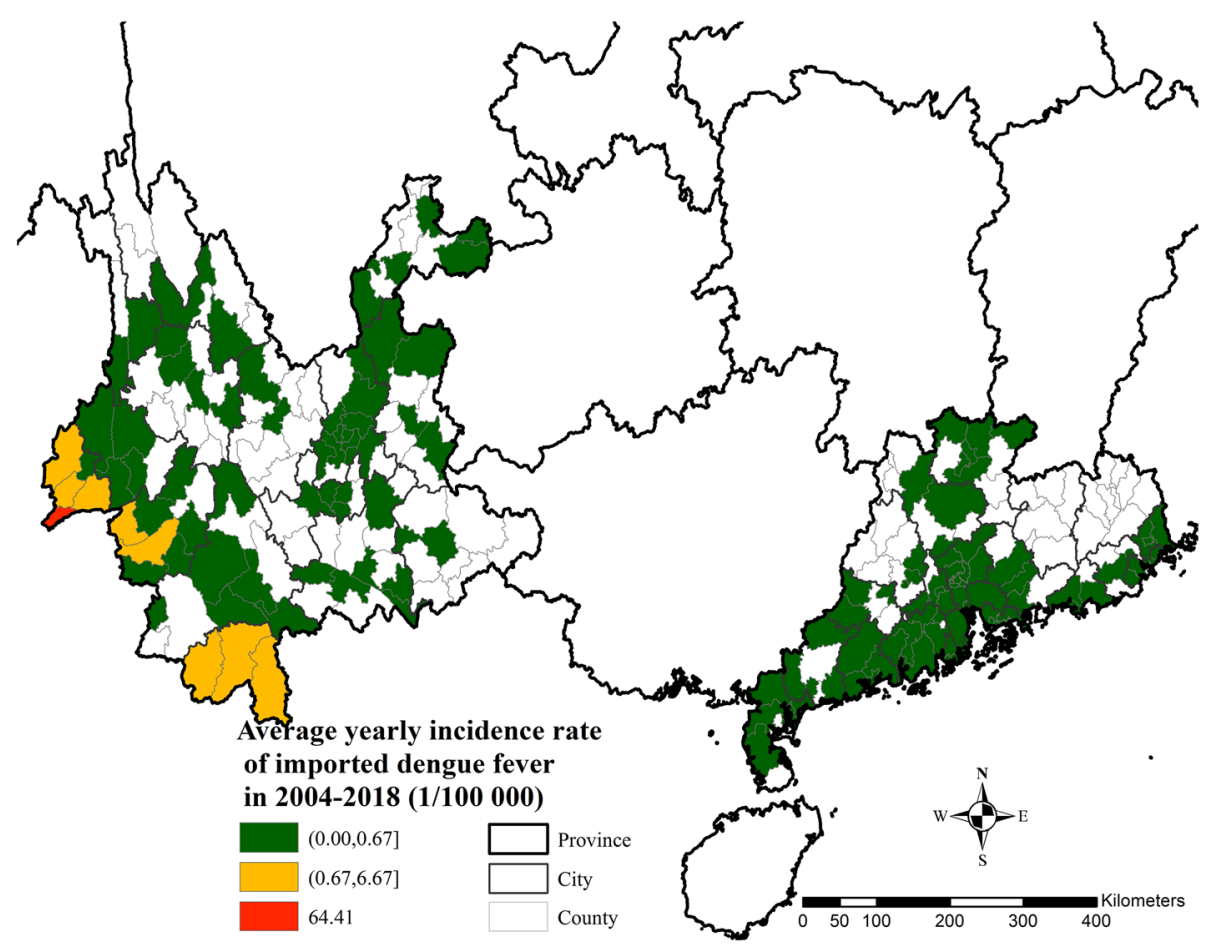

Fig. 4 Spatial distribution of imported dengue fever in GD and YN, 2004-2018. (Fig. 4 was created using ArcGIS version 10.5 by ourselves. Its license number was SO20160927002)

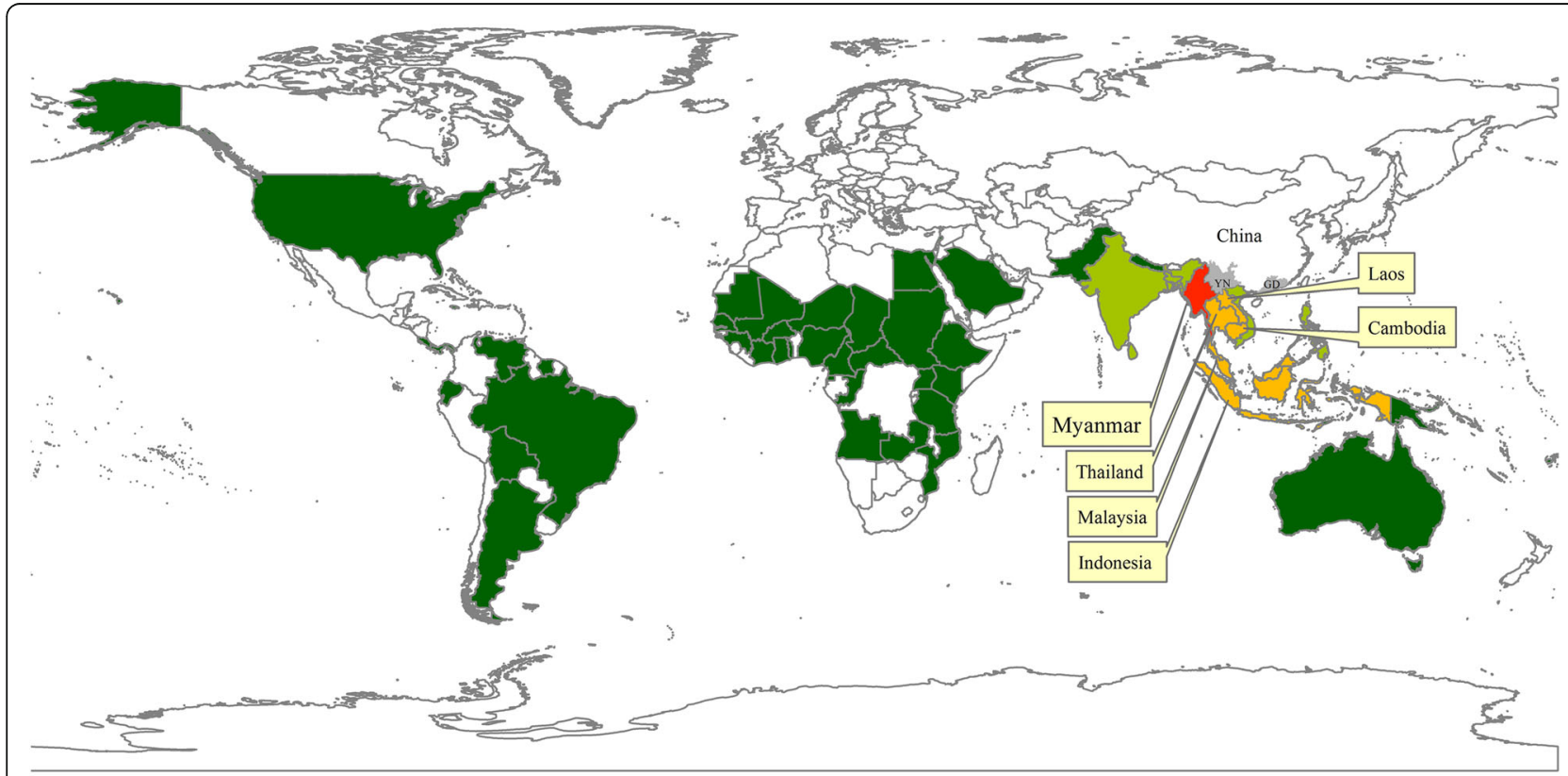

Imported dengue cases during 2004-2018

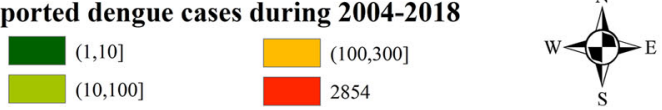

$\begin{array}{llll}0 & 1,4002,800 \quad 5,600 & 8,400 \quad 11,200\end{array}$

2854

Fig. 5 Spatial distribution of the origins of imported dengue fever in GD and YN, 2004-2018. (Fig. 5 was created using ArcGIS version 10.5 by ourselves. Its license number was SO20160927002) 
Table 6 GDP comparison in GD and YN, 2018

\begin{tabular}{lll}
\hline & GD & YN \\
\hline GDP (0.1Billion RMB) & $97,277.77$ & $17,881.12$ \\
The primary industry (0.1Billion RMB) & 3831.44 & 2498.86 \\
The secondary industry (0.1Billion RMB) & $40,695.15$ & 6975.44 \\
The third industry (0.1Billion RMB) & $52,751.18$ & 8424.82 \\
Per capita GDP (RMB/Person) & 86,412 & 37,136 \\
\hline
\end{tabular}

[27-29]. By occupation, there were similarities with the majority affected being house worker or unemployed, retiree, and businessman for indigenous cases, and businessman for the imported cases. Farmers accounted for a larger proportion of dengue cases in $\mathrm{YN}$, which was determined by the industrial structure (Table 5). To address the burden of dengue fever in China, it is necessary to increase the level of knowledge of dengue prevention among people in these occupational categories.

There also existed some limitations to this research. Data quality of dengue case reports from CNNDS should be improved. The remarks in the case report field, described imported sources as foreign countries, used a simple case definition for imported or indigenous cases, or for the process of disease onset and medical treatment. Therefore, the descriptions of the remarks were not standardised. Furthermore, a few remarks were missing. However, dengue cases were divided into indigenous or imported cases mainly based on these remarks. Therefore, there existed some inevitable errors in the division of the cases. Numerous occupational types were unreported; thus, this could have led to missing data on some groups with dengue fever. Above all, these limitations might have influenced the results of this study.

\section{Conclusion}

Dengue fever occurred mostly in GD and YN. This research provided valuable information on the epidemiological characteristics of dengue fever in GD and YN, from 2004 to 2018 by using statistical methods and spatial analysis. GD had a much higher indigenous incidence rate, but a much lower imported incidence rate during 20042018. Dengue fever showed similar seasonal patterns in YN and GD. There existed clustering for dengue fever. Most dengue cases in YN were clustered in the southwestern border while most cases in GD occurred in the Pearl River Delta region. Thailand, Cambodia, and Malaysia were the top three sources of imported cases in GD. Myanmar and Laos were the main sources of imported cases in YN. There was a strong male predominance among imported cases and an almost equal gender distribution for indigenous cases. Most indigenous and imported cases occurred among 21-50 years old. Similar occupational categories were associated with dengue cases including house worker or unemployed, retiree, and businessman. Furthermore, farmers accounted for a larger proportion of dengue cases in YN. An understanding of the differences in epidemiological characteristics of dengue fever in GD and YN is helpful for the development of targeted, strategic plans, and for implementing effective public health prevention measures.

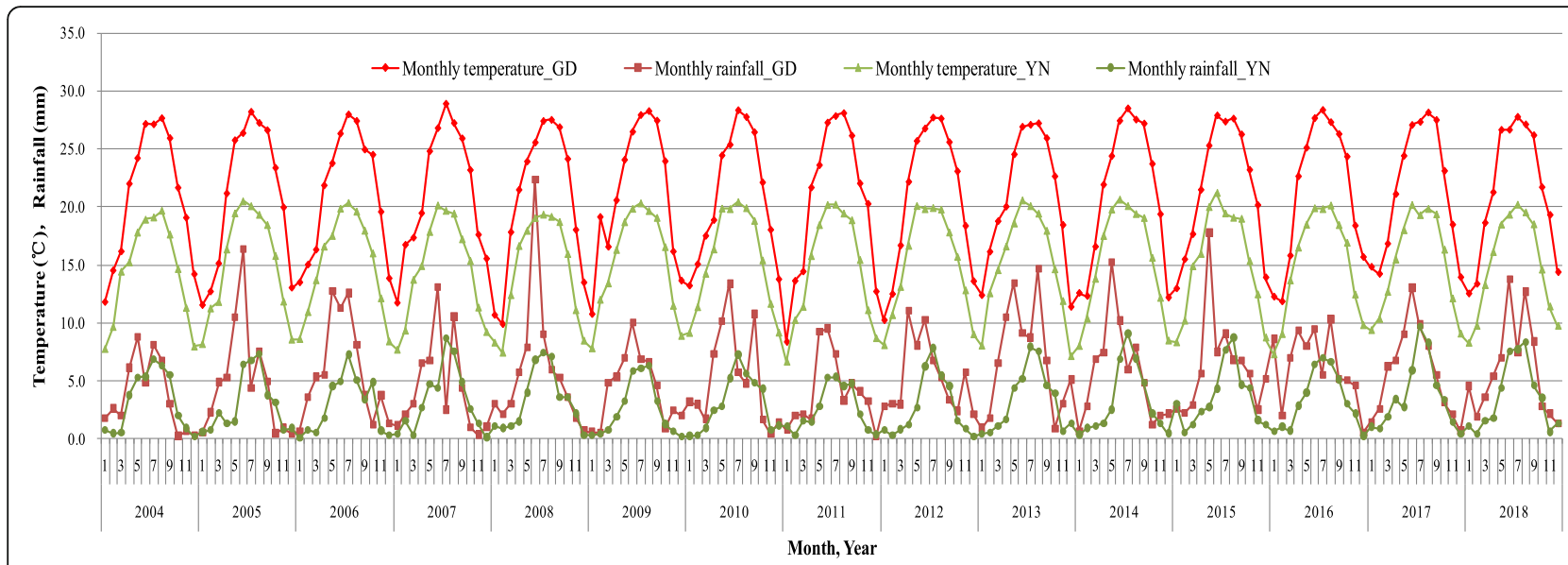

Fig. 6 Monthly temperature and monthly rainfall in GD and YN, 2004-2018 


\section{Abbreviations}

GD: Guangdong; YN: Yunnan; GDP: Gross domestic product; China CDC: Chinese Centre for Disease Control and Prevention; CNNDS: Chinese National Notifiable Infectious Disease Reporting Information System.

\section{Acknowledgements}

We thank the staffs at the hospitals, local health department, and country, district-, prefecture-, and provincial-level CDCs for their valuable assistance in coordinating the data collection.

\section{Authors' contributions}

QL initiated the study. YY collected the data, cleaned the data, performed the analysis and drafted the manuscript. XL and HW contributed to the design of the work. MX contributed to data interpretation. All authors revised the manuscript. All authors have read and approved the manuscript.

\section{Funding}

This study was supported by National Key R\&D Program of China (2020YFC1200100), National Major Science and Technology Project (2017ZX10303404004003 and 2017ZX10303404004004) and the China Prosperity Strategic Program Fund (SPF) 2015-16 (Project Code: 15LCI1). The funders had no role in study design, data collection and analysis, or preparation of the manuscript.

\section{Availability of data and materials}

Daily dengue case reports were from CNNDS (http://www.chinacdc.cn/). The vector data of Chinese administrative divisions were from CNNDS (http:// www.chinacdc.cn/). Monthly average of daily temperature observation data were from Library for Climate Studies of Chinese Meteorological Administration (http://data.cma.cn/). GDP was obtained from National Bureau of Statistics of China (http://www.stats.gov.cn/). Populations in 2004-2018 were from Bureau of Statistics of Yunnan (http://stats.yn.gov.cn/) and Bureau of Statistics of Guangdong (http://stats.gd.gov.cn/).

\section{Declarations}

\section{Ethics approval and consent to participate}

Not applicable. No human or animal samples were included in the research presented in this article, therefore ethical approval was not necessary for this research according to Measures for ethical review of biomedical research involving human beings (No. 11 of National health commission of the People's Republic of China. http://www.xinyu.gov.cn/fg3tg/201610/f57487a5 ef8f4bf3a6df2210956f1963.shtml). We obtained the permissions from Chinese Center for Disease Control and Prevention, Chinese Meteorological Administration, National Bureau of Statistics of China, Bureau of Statistics of Yunnan and Bureau of Statistics of Guangdong to access all the data in this research. As a member of Chinese Center for Disease Control and Prevention, data analysis of infectious disease was one part of my job, and had the license to access dengue cases. Other data in this research were nearly public, and I just needed to apply an account to access them. Before submission, the manuscript also passed the examination of our institute.

\section{Consent for publication}

Not applicable.

\section{Competing interests}

The authors declare that they have no competing interests.

\section{Author details}

'State Key Laboratory of Infectious Disease Prevention and Control, National Institute for Communicable Disease Control and Prevention, Chinese Centre for Disease Control and Prevention, Beijing 102206, People's Republic of China. ${ }^{2}$ Shandong First Medical University \& Shandong Academy of Medical Sciences, Tai'an, People's Republic of China.
Received: 27 September 2020 Accepted: 18 June 2021

Published online: 13 July 2021

\section{References}

1. Bhatt $\mathrm{S}$, Gething PW, Brady OJ, Messina JP, Farlow AW, Moyes $\mathrm{CL}$, et al. The global distribution and burden of dengue. Nature. 2013;496(7446):504-7. https://doi.org/10.1038/nature12060.

2. Sang S, Gu S, Bi P, Yang WZ, Xu L, Yang J, et al. Predicting unprecedented dengue outbreak using imported cases and climatic factors in Guangzhou, 2014. PLoS Negl Trop Dis. 2015;9(5):e0003808. https://doi.org/10.1371/journa I pntd.0003808.

3. Guzman MG, Harris E. Dengue. Lancet. 2015;385(9966):453-65. https://doi. org/10.1016/S0140-6736(14)60572-9.

4. Endy TP, Anderson KB, Nisalak A, Yoon I, Green S, Rothman A, et al. Determinants of inapparent and symptomatic dengue infection in a prospective study of primary school children in Kamphaeng Phet, Thailand. PLoS Negl Trop Dis. 2011;5(3):e975. https://doi.org/10.1371/journal.pntd. 0000975.

5. Balmaseda A, Standish K, Mercado JC, Matute JC, Tellez Y, Saborio S, et al. Trends in patterns of dengue transmission over 4 years in a pediatric cohort study in Nicaragua. J Infect Dis. 2010;201(1):5-14. https://doi.org/10.1086/64 8592.

6. WHO/TDR. Dengue guidelines for diagnosis, treatment, prevention and control. New Edition. Geneva: World Health Organization; 2009.

7. Guo C, Zhou Z, Wen Z, Liu Y, Zeng C, Xiao D, et al. Global epidemiology of dengue outbreaks in 1990-2015: a systematic review and meta-analysis. Front Cell Infect Microbiol. 2017;7:317. https://doi.org/10.3389/fcimb.2017. 00317.

8. Chen B, Liu QY. Dengue fever in China. Lancet. 2015;385(9978):1621-2. https://doi.org/10.1016/S0140-6736(15)60793-0.

9. Yue Y, Sun J, Liu X, Ren D, Liu Q, Xiao X, et al. Spatial analysis of dengue fever and exploring its environmental and socio-economic risk factors using ordinary least squares: a case study in five districts, Guangzhou City, China, 2014. Int J Infect Dis. 2018;75:39-48. https://doi.org/10.1016/j.jijd.2018.07.023.

10. Wu J, Lun Z, James A. Review: dengue fever in mainland China. Am J Trop Med Hyg. 2010;83(3):664-71. https://doi.org/10.4269/ajtmh.2010.09-0755.

11. Lai SJ, Huang ZJ, Zhou H, Anders KL, Perkins TA, Yin W, et al. The changing epidemiology of dengue in China 1990-2014: a descriptive analysis of 25 years of nationwide surveillance data. BMC Med. 2015;13(1):100. https://doi. org/10.1186/s12916-015-0336-1

12. Sun JM, Lu L, Wu HX, Yang J, Xu L, Sang SW, et al. Epidemiological trends of dengue in mainland China, 2005-2015. Int J Infect Dis. 2017;57:86-91. https://doi.org/10.1016/j.ijid.2017.02.007.

13. Ministry of Health of the People's Republic of China. Diagnostic criteria and principle of management of dengue (WS 216-2001) [in Chinese]. Beijing: Standards Press of China; 2001. p. 1-12

14. Ministry of Health of the People's Republic of China. Diagnostic criteria for dengue (WS 216-2008) [in Chinese]. Beijing: People's Medical Publishing House; 2008. p. 1-17.

15. ESRI. ArcGIS 10.3 help. ESRI Press 2017.

16. Lai LW. Influence of environmental conditions on asynchronous outbreaks of dengue disease and increasing vector population in Kaohsiung, Taiwan. Int J Environ Health Res. 2011;21(2):133-46. https://doi.org/10.1080/ 09603123.2010 .515670

17. Lippi CA, Stewart-lbarra AM, Muñoz AG, Borbor-Cordova MJ, Mejía R, Rivero $\mathrm{K}$, et al. The social and spatial ecology of dengue presence and burden during an outbreak in Guayaquil, Ecuador, 2012. Int J Environ Res Public Health. 2018;15(4):827. https://doi.org/10.3390/ijerph15040827.

18. Liu K, Sun J, Liu X, Li R, Wang Y, Lu L, et al. Spatiotemporal patterns and determinants of dengue at county level in China from 2005-2017. Int J Infect Dis. 2018;77:96-104. https://doi.org/10.1016/j.jijd.2018.09.003.

19. Liu Q, Xu W, Lu S, Jiang J, Zhou J, Shao Z, et al. Landscape of emerging and re-emerging infectious diseases in China impact of ecology, climate, and behavior. Front Med. 2018;12(1):3-22. https://doi.org/10.1007/s11684-0170605-9.

20. Yue YJ, Liu XB, Xu M, Ren DS, Liu QY. Epidemiological dynamics of dengue fever in mainland China, 2014-2018. Int J Infect Dis. 2019;86:82-93. https:// doi.org/10.1016/j.jiji.2019.06.015.

21. Kurniawati D. Rising number of dengue fever cases in Indonesia. 2013. http://www.aseantoday.com/2013/07/rising-number-of-den-gue-fever-casesin-indonesia/. 
22. Lefevre AS. Thailand suffers worst dengue epidemic in more than 20 years. 2013. http://www.trust.org/item/20131024100249-aqxiv/.

23. Ng LC, Chem YK, Koo C, Mudin RN, Amin FM, Lee KS, et al. 2013 dengue outbreaks in Singapore and Malaysia caused by different viral strains. Am J Trop Med Hyg. 2015;92(6):1150-5. https://doi.org/10.4269/ajtmh.14-0588.

24. Kutsuna S, Kato Y, Moi ML, Kotaki A, Ota M, Shinohara K, et al. Autochthonous dengue fever, Tokyo, Japan, 2014. Emerg Infect Dis. 2015; 21(3):517-20. https://doi.org/10.3201/eid2103.141662.

25. Ling F, Fan W, Lin J, Yan J, Lv H, Fu T, et al. Epidemiological survey on a dengue outbreak in Yiwu, Zhejiang Province. Dis Surveillance. 2010;25: 757-9.

26. World Health Organization: Dengue fever and dengue hemorrhagic fever. 2014. http://www.who.int/mediacentre/factsheets/fs117/en (2009). Accessed 27 July 2014.

27. Xu G, Dong H, Shi N, Liu S, Zhou A, Cheng Z, et al. An outbreak of dengue virus serotype 1 infection in Cixi, Ningbo, People's republic of China, 2004, associated with a traveler from Thailand and high density of Aedes albopictus. Am J Trop Med Hyg. 2007;76(6):1 182-8. https://doi.org/10.4269/a jtmh.2007.76.1182

28. Huang XY, Ma HX, Wang HF, Du YH, Su J, Li XL, et al. Outbreak of dengue fever in Central China, 2013. Biomed Environ Sci. 2014;27(11):894-7. https:// doi.org/10.3967/bes2014.125.

29. Guo RN, Lin JY, Li LH, Ke CW, He JF, Zhong HJ, et al. The prevalence and endemic nature of dengue infections in Guangdong, South China: an epidemiological, serological, and etiological study from 2005-2011. PLoS One. 2014;9(1):e85596. https://doi.org/10.1371/journal.pone.0085596.

\section{Publisher's Note}

Springer Nature remains neutral with regard to jurisdictional claims in published maps and institutional affiliations.

Ready to submit your research? Choose BMC and benefit from:

- fast, convenient online submission

- thorough peer review by experienced researchers in your field

- rapid publication on acceptance

- support for research data, including large and complex data types

- gold Open Access which fosters wider collaboration and increased citations

- maximum visibility for your research: over $100 \mathrm{M}$ website views per year

At $\mathrm{BMC}$, research is always in progress.

Learn more biomedcentral.com/submissions 